\title{
Investigation of Geographical Origin and Production Method of L(+)-Tartaric Acid by Isotopic Analyses with Chemometrics
}

\author{
Glaucia Danielle Leirose ${ }^{1}$, Marie-Florence Grenier-Loustalot ${ }^{2}$ and Arno Heeren de Oliveira ${ }^{1}$ \\ 1. UFMG (Federal University of Minas Gerais), Av. Pres. Antônio Carlos, 6627 Pampulha, Belo Horizonte, MG, Brazil \\ 2. ERINI (European Research Institute on Natural Ingredients)-4, Traverse Dupont, Grasse, France
}

\begin{abstract}
The determination of the geographical origin as well as the adulteration of natural products is a technical problem due to similar chemical composition between an adulterant and the original. It is assumed that tartaric acid comes from natural sources, however there is no specific regulation for this claim. This paper describes the use of isotope mass spectrometry associated with chemometrics to classify different samples of tartaric acid. The results showed that the variables $\delta^{13} \mathrm{C}, \delta^{18} \mathrm{O}$ and $\delta^{2} \mathrm{H}$ allowed the discrimination of tartaric acid samples by geographical origin and production method. By using a combination of chemometric analysis it was possible to confirm a notoriousseparation of the samples. Thus, this is a promising method to be applied in the quality control and authenticity of tartaric acid.
\end{abstract}

Key words: Tartaric acid, multi-isotope analysis, food authenticity, geographical origin, isotopic mass spectrometry.

\section{Introduction}

$\mathrm{L}(+)$-Tartaric acid is a natural compound present in several plant species; principally grapes, bananas, and tamarind. This organic acid is a crystalline white solid, odorless and has strong tart taste. Besides being an important controller of the acidity of the wine, tartaric acid and its salts have a vast application in food and pharmaceutical industries [1].

There are two methods commonly used to obtain tartaric acid on a large scale, natural and synthetic.

In the natural way, raw materials are by-products of the wine production: crude tartars, lees, and argols. These materials have large amount of tartaric salts, mainly potassium bitartrate and calcium tartrate. After a pre-treatment step, calcium carbonate or calcium hydroxide solution is added to raw materials, in order to form calcium tartrate. Then, calcium tartrate is converted to tartaric acid via a sulfuric acid treatment, followed by filtration and crystallization $[2,3]$.

Corresponding author: Arno Heeren de Oliveira, Ph.D., professor, research field: nuclear engineering.
The second way to produce tartaric acid is by biotechnological synthesis. This method is based on the conversion of cis-epoxysuccinic acid into $\mathrm{L}(+)$-tartaric acid. Cis-epoxysuccinate is formed by the oxidation of maleic anhydride, a petroleum derivative. An enzyme capable of hydrolyzing the epoxy group of cis-epoxysuccinate is applied to this process [4]. The main advantages of this synthetic method consist of low cost, abundance of cis-epoxysuccinic acid, and highly selective biotransformation in L-tartaric acid.

The determination of the production method and geographical origin of tartaric acid is not evident due to high purity of the final product. The similarity level between natural and synthetic compounds hampers the quality control. Currently, European regulation allows only the use of natural tartaric acid $[5,6]$. To avoid adulteration, diverse analysis has been used to track the tartaric acid origin [7].

Isotopic analysis has been applied to verify food and beverage authenticity and has shown good results [8-10]. The method of analysis by IRMS 
(isotope-ratio mass spectrometry) exploits differences of origin, which leave a recognizable trace in the final product. Thus in the case of tartaric acid, ${ }^{13} \mathrm{C},{ }^{18} \mathrm{O}$ and ${ }^{2} \mathrm{H}$ isotopes could yield very interesting information about natural or synthetic origin and geographical provenance. Carbon isotopes are affected by botanical origins and photosynthetic pathway, predominantly. A single plant with photosynthetic pathway $\mathrm{C} 3$ produces $\mathrm{L}(+)$-tartaric acid, besides this plant is cultivated under very strict climatic conditions [11]. Consequently, the ${ }^{13} \mathrm{C} /{ }^{12} \mathrm{C}$ ratio is restricted to a small range. Unlike the production of synthetic tartaric acid, the petrol source allows a wide range of values for carbon isotope ratio, which can generate superimposed values on the natural tartaric acid. In light of this, carbon isotope analysis is not sufficient to distinguish the tartaric acid source, although it allows the identification of synthetic products that are outside the natural range. The isotopic ratio ${ }^{18} \mathrm{O} /{ }^{16} \mathrm{O}$ in natural and synthetic tartaric acid are distinctive due to their different source. The production of synthetic tartaric acid uses ground water as the only source of oxygen and hydrogen. For natural tartaric acid, plants obtain oxygen by multiples ways, such as water precipitation absorbed via roots, and atmospheric $\mathrm{CO}_{2}$ and $\mathrm{O}_{2}$ [12]. Moreover, plants transpiration and/or exchange with atmospheric vapor causes enrichment of heavy oxygen. Due to these differences and studies, it is generally agreed that $\delta^{18} \mathrm{O}$ is higher in the natural tartaric acid than in the synthetic one [7, 13]. The hydrogen atoms present in natural tartaric acid come from precipitation water, which make the ${ }^{2} \mathrm{H} /{ }^{1} \mathrm{H}$ ratio extremely dependent on region and climate [14].

Multivariate analysis was applied to find correlations between isotopic data and external factors, i.e., production method and geographical origin. Chemometrics analysis enabled the classification of a large number of samples in similar groups $[15,16]$. Different multivariate statistics techniques were used for comparison and verification of the results.

\section{Materials and Methods}

In this study, 35 samples of tartaric acid were collected and classified according to production method and geographic region. All samples were monitored with regards to purity and according to the melting point, they present purity above $95.5 \%$. Tartaric acid samples were acquired from different countries and types of production.

The high purity and homogeneity of the samples allowed IRMS analysis without requiring complex preparation. Samples all crushed cryogenically to ensure homogeneous size distribution. In addition, they were kept in a desiccator under inert atmosphere to avoid errors due to environmental conditions.

\subsection{Isotope Measurements}

Stable isotopes determinations were performed using an elemental analyzer coupled to isotope-ratio mass spectrometer. The measurements of $\delta^{13} \mathrm{C}$ were carried out in an Elemental Analyser Flash EA1112 coupled to an IRMS Delta V Plus, both from Thermo Scientific. Samples were introduced into a combustion unit maintained at $1,000^{\circ} \mathrm{C}$ under a stream of oxygen and helium. Carbon was converted to $\mathrm{CO}_{2}$ and the signals received on the masses 44,45 and 46 were used to measure the isotopic ${ }^{13} \mathrm{C} /{ }^{12} \mathrm{C}$.

The measurements of $\delta^{2} \mathrm{H}$ and $\delta^{18} \mathrm{O}$ were carried out in a high TC/EA (temperature conversion elemental analyzer) from Thermo Finnigan together with IRMS Delta V Plus. The sample was deposited into a pyrolysis unit at $1,400{ }^{\circ} \mathrm{C}$ containing carbon black in a ceramic tube, filled itself of carbon black. The hydrogen and oxygen from the samples were converted to $\mathrm{H}_{2}$ and $\mathrm{CO}$. The ratio ${ }^{2} \mathrm{H} /{ }^{1} \mathrm{H}$ was calculated based on the measured signals to the masses 2 and 3 of $\mathrm{H}_{2}$. Then the ${ }^{18} \mathrm{O} /{ }^{16} \mathrm{O}$ ratio was determined using the signals collected for the masses 28 and 30 of $\mathrm{CO}$.

The results of isotopic values were obtained by the standard notation Delta $(\delta)$ as per mil (\%), as in Eq. (1).

$$
\delta=\left[\left(\mathrm{R}_{\text {sample }}-\mathrm{R}_{\text {standard }}\right) / \mathrm{R}_{\text {standard }}-1\right] \times 1000
$$


where $\mathrm{R}_{\text {sample }}$ and $\mathrm{R}_{\text {standard }}$ are ${ }^{13} \mathrm{C} /{ }^{12} \mathrm{C}$ or ${ }^{2} \mathrm{H} /{ }^{1} \mathrm{H}$ or ${ }^{18} \mathrm{O} /{ }^{16} \mathrm{O}$ ratios of the sample and standard, respectively. International standard used for ${ }^{13} \mathrm{C}$ was VPDB (Vienna Pee Dee Belemnite) and for ${ }^{2} \mathrm{H} /{ }^{18} \mathrm{O}$ was VSMOW (Vienna Standard Mean Ocean Water).

\subsection{Statistical Analysis}

Multivariate statistical techniques were performed using Minitab ${ }^{\circledR}$ Statistical Software version 17.1.0 (Minitab Inc., State College, USA). PCA (Principal components analysis), cluster analysis, and DA (discriminant analysis) were the techniques applied. Isotopic variables were treated according to their production method and geographical origin.

PCA is a mathematical treatment used to simplify data matrix based on the correlation between the variables. High collinearity is a strong indication that it is possible to find new bases that best represent the information provided in the measures. It enables to demonstrate differences between the various samples or groups of samples through new variables formed, referred as principal components.

Cluster analysis predicts groups of samples when the groups are not yet known. This exploratory data analysis tool classifies objects into clusters according to their similarity if they belong to the same cluster or distance if they are in different clusters.

In discriminant analysis groups are known or predetermined. This statistical treatment consists in finding mathematical functions to distingue samples in groups.

\section{Results and Discussion}

The experimental data of carbon, oxygen and hydrogen stable isotope ratio are summarized in Table 1. Tartaric acid samples were divided by their production method. While natural tartaric acid samples were classified by geographical origin. The isotope ratios for carbon and oxygen in natural samples were consistent with previous studies [7, 13].

\subsection{Production Method}

All three dataset $\left(\delta^{13} \mathrm{C}+\delta^{18} \mathrm{O}+\delta^{2} \mathrm{H}\right)$ were subjected to PCA for production method for all 35 samples, Fig. 1. The graph depicts a clear separation between natural and synthetic tartaric acid using the first two principal components. Only one outlier was identified, a sample of synthetic tartaric acid. The outlier was caused by very high level of $\delta^{13} \mathrm{C}$. If this outlier is removed from the PCA, there is no significant change in the segregation of natural and synthetic groups. One can see that synthetic samples have dispersed values. This trend is perceived because there is no standardization of the synthetic production made in different parts of the world. Also, the difference in isotope composition of water used in the synthesis is an important factor that contributes to this separation.

Discrimination analysis confirmed the PCA's results. All samples were correct classified, $100 \%$ for overall performance and $100 \%$ for cross-validation.

\subsection{Geographic Origin}

Natural samples were classified according to their geographic origin. Once again, a proper separation was observed using PCA $\left(\delta^{13} \mathrm{C}+\delta^{18} \mathrm{O}+\delta^{2} \mathrm{H}\right)$, especially between samples from Argentina and from European countries as shown in Fig. 2. The combination

Table 1 Stable isotope ratios of carbon, oxygen, and hydrogen for different production methods and geographical origins.

\begin{tabular}{|c|c|c|c|c|c|c|c|c|c|c|c|c|}
\hline & \multicolumn{4}{|c|}{$\delta^{13} \mathrm{C}$} & \multicolumn{4}{|c|}{$\delta^{18} \mathrm{O}$} & \multicolumn{4}{|c|}{$\delta^{2} \mathrm{H}$} \\
\hline & Mean & SD & Min & Max & Mean & SD & Min & Max & Mean & SD & Min & Max \\
\hline \multicolumn{13}{|l|}{ Production method } \\
\hline Natural $(n=24)$ & $-22,65$ & 0,39 & $-23,30$ & $-21,81$ & 28,13 & 2,75 & 23,43 & 34,20 & $-81,92$ & 22,27 & $-126,50$ & $-49,00$ \\
\hline Synthetic $(n=11)$ & $-25,06$ & 4,20 & $-31,53$ & $-21,19$ & 17,40 & 1,78 & 13,85 & 19,60 & $-40,73$ & 21,30 & $-72,00$ & $-9,00$ \\
\hline \multicolumn{13}{|l|}{ Geographical origin } \\
\hline Europe $(n=18)$ & $-22,58$ & 0,44 & $-23,23$ & $-21,81$ & 29,25 & 2,15 & 26,40 & 34,20 & $-70,33$ & 10,69 & $-85,00$ & $-49,00$ \\
\hline South America $(n=6)$ & $-22,85$ & 0,28 & $-23,30$ & $-22,55$ & 24,79 & 1,40 & 23,43 & 27,70 & $-116,67$ & 8,69 & $-126,50$ & $-103,00$ \\
\hline
\end{tabular}



Acid by Isotopic Analyses with Chemometrics

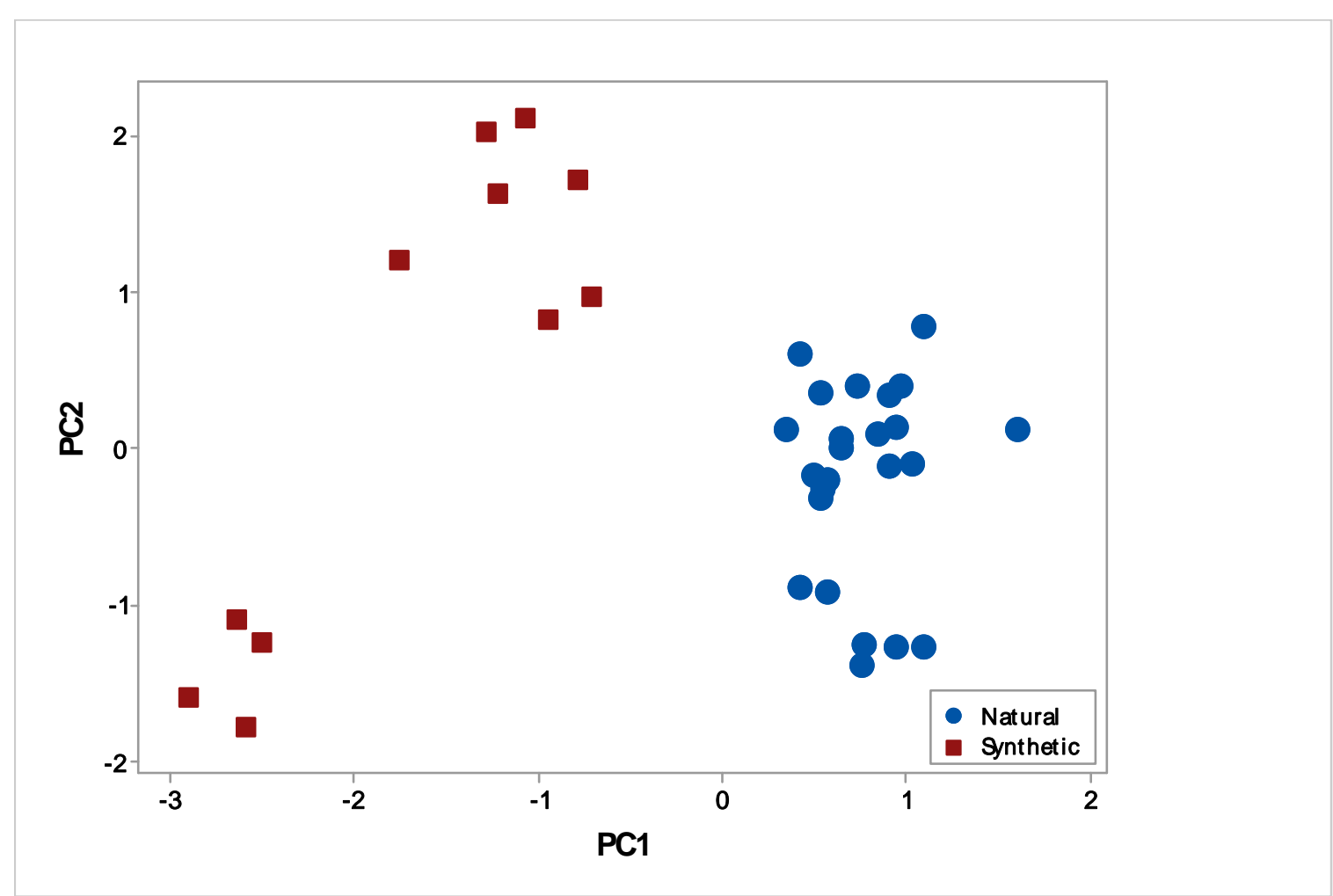

Fig. 1 PCA plot for production method using the first two principal components for $\delta^{13} \mathrm{C}, \delta^{18} \mathrm{O}$ and $\delta^{2} \mathrm{H}$ data.

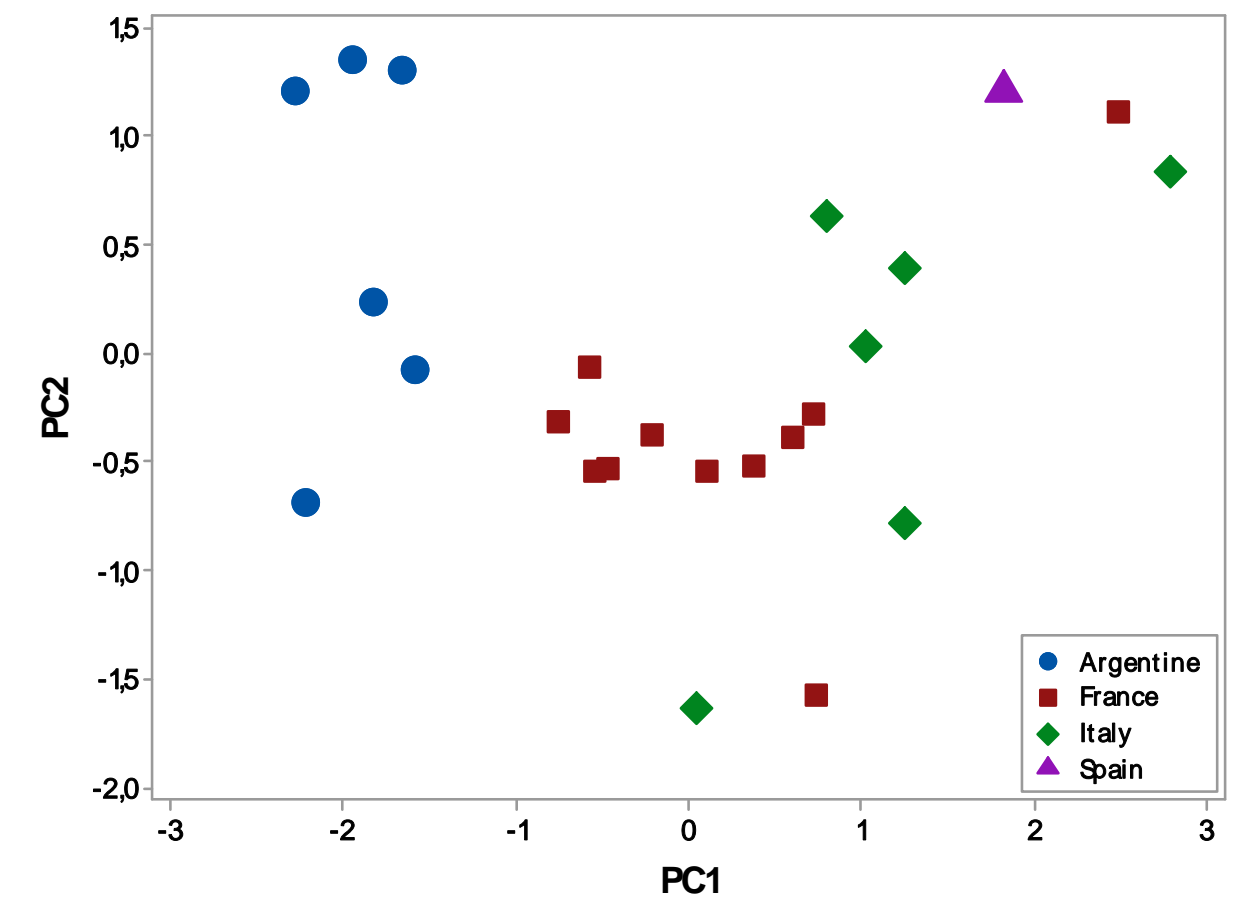

Fig. 2 PCA plot for geographical origin using the first two principal components for $\delta^{13} \mathrm{C}, \delta^{18} \mathrm{O}$ and $\delta^{2} \mathrm{H}$. 
of two isotope ratio $\left({ }^{2} \mathrm{H} /{ }^{1} \mathrm{H}\right.$ and $\left.{ }^{18} \mathrm{O} /{ }^{16} \mathrm{O}\right)$ that provide information about geographical origin was crucial for this differentiation.

In the same manner as the production method, geographical separation was confirmed with DA. Stable isotope ratio analysis was able to correctly classify $100 \%$ of the samples for overall performance and $100 \%$ for cross-validation considering Argentina and European countries. For discrimination made by country, the overall classification decreased to $78.3 \%$ while the cross-validation reduced to $73.9 \%$. The samples classified erroneously were from France and Italy. Isotopic ratio of hydrogen and oxygen depends on the geographic region and climate, since they have in common the origin from precipitation water [14]. As France and Italy are adjacent regions, it explains the similar data profile.

\section{Conclusions}

This study described a novel method combining stable isotope ratio analysis with multivariate statistics data handling to classify tartaric acid into different groups based on the production method and geographical origin. The combination of $\delta^{13} \mathrm{C}, \delta^{18} \mathrm{O}$ and $\delta^{2} \mathrm{H}$ data is recommended, since it allows classification in two groups with the same data. PCA was an accurate tool for obtaining the correct classification, which has been confirmed with DA analysis. The large number of samples used in this study confirms the applicability of this technique to quality control of tartaric acid.

\section{Acknowledgment}

The authors thank CAPES and $\mathrm{CNPq}$ for the support.

\section{References}

[1] Yalcin, D., Ozcalik, O., Altiok, E., and Bayraktar, O. 2008. "Characterization and Recovery of Tartaric Acid from Wastes of Wine and Grape Juice Industries." Journal of Thermal Analysis and Calorimetry 94 (3): 767-71.
[2] Kassaian, J. M. 2000. "Tartaric Acid.” In Ullmann's Encyclopedia of Industrial Chemistry, edited by Wiley-VCH Verlag GmbH \& Co. KGaA.

[3] Blair, G. T., and DeFraties, J. J. 2000. "Hydroxy Dicarboxylic Acids." In Kirk-Othmer Encyclopedia of Chemical Technology, edited by John Wiley \& Sons, Inc.

[4] Rosenberg, M., Mikova, H., and Kristofikova, L. 1999. "Production of L-tartaric Acid by Immobilized Bacterial Cells Nocardia Tartaricans." Biotechnology Letters 21 (6): 491-5.

[5] European Commission. 2000. "No 1622/2000 of 24 July 2000 Laying Down Certain Detailed Rules for Implementing Regulation (EC) No 1493/1999 on the Common Organisation of the Market in Wine and Establishing a Community Code of Oenological Practices and Processes." Commission Regulation (EC) 194: 1-44.

[6] Council of the European Union. 1999. "Council Regulation (EC) No 1493/1999 of 17 May 1999 on the Common Organisation of the Market in Wine." Commision Regulations (EC) 179: 1-84.

[7] Serra, F., Reniero, F., Guillou, C. G., Moreno, J. M., Marinas, J. M., and Vanhaecke, F. 2005. "13C and $18 \mathrm{O}$ Isotopic Analysis to Determine the Origin of L-tartaric Acid.” Rapid Communications in Mass Spectrometry 19 (10): 1227-30.

[8] Jiang, W., Xue, J., Xiang, L., De-liang, W., Yang, G., and Lu, W. 2015. "The Application of SNIF-NMR and IRMS Combined with $\mathrm{C}, \mathrm{H}$ and $\mathrm{O}$ Isotopes for Detecting the Geographical Origin of Chinese Wines." International Journal of Food Science \& Technology 50 (3): 774-81.

[9] Schlesier, K., Fauhl-Hassek, C., Forina, M., Cotea, V., Kocsi, E., Schoula, R., van Jaarsveld, F., and Wittkowski, R. 2009. "Characterisation and Determination of the Geographical Origin of Wines. Part I: Overview." European Food Research and Technology 230 (1): 1.

[10] Zyakun, A. M., Oganesyants, L. A., Panasyuk, A. L., Kuz'mina, E. I., Shilkin, A. A., Baskunov, B. P., Zakharchenko, V. N., and Peshenko, V. P. 2013. "Mass Spectrometric Analysis of the $13 \mathrm{C} / 12 \mathrm{C}$ Abundance Ratios in Vine Plants and Wines Depending on Regional Climate Factors (Krasnodar Krai and Rostov Oblast, Russia)." Journal of Analytical Chemistry 68 (13): 1136-41.

[11] Costinel, D., Tudorache, A., Ionete, R. E., and Vremera, R. 2011. "The Impact of Grape Varieties to Wine Isotopic Characterization.” Analytical Letters 44 (18): 2856-64.

[12] Santesteban, L. G., Miranda, C., C., Barbarin, I. and Royo, J. B. 2015. "Application of the Measurement of the Natural Abundance of Stable Isotopes in Viticulture: A Review." Australian Journal of Grape and Wine Research 21 (2): 157-67. 
[13] Moreno, R. J. M., Cosofret, S., Reniero, F., Guillou, C., and Serra, F. 2007. "Control of Oenological Products: Discrimination between Different Botanical Sources of L-tartaric Acid by Isotope Ratio Mass Spectrometry." Rapid Communications in Mass Spectrometry 21 (15): 2447-50.

[14] Kelly, S., Heaton, K., and Hoogewerff, J. 2005. "Tracing the Geographical Origin of Food: The Application of Multi-element and Multi-isotope Analysis." Trends in Food Science \& Technology 16 (12): 555-67.
[15] Tzouros, N. E., and Arvanitoyannis, I. S. 2001. "Agricultural Produces: Synopsis of Employed Quality Control Methods for the Authentication of Foods and Application of Chemometrics for the Classification of Foods According to Their Variety or Geographical Origin." Crit Rev Food Sci Nutr 41 (4): 287-319.

[16] Defernez, M., and Kemsley, E. K. 1997. "The Use and Misuse of Chemometrics for Treating Classification Problems." TrAC Trends in Analytical Chemistry 16 (4): 216-21. 